Pacific Journal of Mathematic 


\title{
THE RECIPROCITY THEOREM FOR DEDEKIND SUMS
}

\author{
L. CARLIT Z
}

1. Introduction. Let $((x))=x-[x]-1 / 2$, where $[x]$ denotes the greatest integer $\leq x$, and put

$$
\bar{s}(h, k)=\sum_{r(\bmod k)}\left(\left(\frac{r}{k}\right)\right)\left(\left(\frac{h r}{k}\right)\right),
$$

the summation extending over a complete residue system $(\bmod k)$. Then if $(h, k)=1$, the sum $\bar{s}(h, k)$ satisfies (see for example [4])

$$
12 h k\{\bar{s}(h, k)+\bar{s}(k, h)\}=h^{2}+3 h k+k^{2}+1 .
$$

Note that $\bar{s}(h, k)=s(h, k)+1 / 4$, where $s(h, k)$ is the sum defined in [4].

In this note we shall give a simple proof of (1.2) which was suggested by Redei's proof [5]. The method also applies to Apostol's extension [1]; [2].

2. A formula for $\overline{\boldsymbol{s}}(h, k)$. We start with the easily proved formula

$$
\left(\left(\frac{r}{k}\right)\right)=-\frac{1}{2 k}+\frac{1}{k} \sum_{s=1}^{k-1} \frac{\rho^{-r s}}{\rho^{s}-1}
$$

$$
\left(\rho=e^{2 \pi i / k}\right),
$$

which is equivalent to a formula of Eisenstein. (Perhaps the quickest way to prove $(2.1)$ is to observe that

$$
\sum_{r=0}^{k-1}\left(\left(\frac{r}{k}\right)\right) \rho^{r s}=\left\{\begin{array}{l}
1 /\left(\rho^{s}-1\right) \\
-1 / 2
\end{array}\right.
$$

inverting leads at once to $(2.1))$.

Now substituting from $(2.1)$ in $(1.1)$ we get 


$$
\begin{aligned}
\bar{s}(h, k) & =\sum_{r}\left\{-\frac{1}{2 k}+\frac{1}{k} \sum_{t=1}^{k-1} \frac{\rho^{-t s}}{\rho^{t}-1}\right\}\left\{-\frac{1}{2 k}+\frac{1}{k} \sum_{s=1}^{k-1} \frac{\rho^{-h r s}}{\rho^{s}-1}\right\} \\
& =\frac{1}{4 k}+\frac{1}{k^{2}} \sum_{s, t=1}^{k-1} \frac{1}{\left(\rho^{s}-1\right)\left(\rho^{t}-1\right)} \sum_{r=0}^{k-1} \rho^{-r(s h+t)}
\end{aligned}
$$

Since the inner sum vanishes unless $s+h t \equiv 0(\bmod k)$, we get

$$
\bar{s}(h, k)=\frac{1}{4 k}+\frac{1}{k} \sum_{k=1}^{k-1} \frac{1}{\left(\rho^{-s}-1\right)\left(\rho^{h s}-1\right)},
$$

or, what is the same thing,

$$
\bar{s}(h, k)=\frac{1}{4 k}+\frac{1}{k} \sum_{\zeta \neq 1} \frac{1}{\left(\zeta^{-1}-1\right)\left(\zeta^{h}-1\right)},
$$

where $\zeta$ runs through the $k$ th roots of unity distinct from 1 .

3. Proof of (1.2) In the next place consider the equation

$$
\left(x^{h}-1\right) f(x)+\left(x^{k}-1\right) g(x)=x-1,
$$

where $f(x), g(x)$ are polynomials, $\operatorname{deg} f(x)<k-1, \operatorname{deg} g(x)<h-1$. Then if $\zeta$ has the same meaning as in (2.2), it is clear from (3.1) that

$$
\left(\zeta^{h}-1\right) f(\zeta)=\zeta-1
$$

Thus by the Lagrange interpolation formula

$$
f(x)=\left(x^{k}-1\right)\left\{\frac{f(1)}{k(x-1)}+\frac{1}{k} \sum_{\zeta \neq 1} \frac{\zeta}{x-\zeta} \frac{\zeta-1}{\zeta^{h}-1}\right\} .
$$

Similarly, if $\eta$ runs through the $h$ th roots of unity,

$$
g(x)=\left\{\frac{g(1)}{h(x-1)}+\frac{1}{h} \sum_{\eta \neq 1} \frac{\eta}{x-\eta} \frac{\eta-1}{\eta^{k}-1}\right\}
$$

Now it follows from (3.1) that $h f(1)+k g(1)=1$; hence substituting from (3.2) and $(3.3)$ in (3.1) we get the identity 


$$
\begin{aligned}
\frac{1}{k} \sum_{\zeta \neq 1} \frac{\zeta}{x-\zeta} \frac{\zeta-1}{\zeta^{h}-1}+\frac{1}{h} \sum_{\eta \neq 1} & \frac{\eta}{x-\eta} \frac{\eta-1}{\eta^{k}-1} \\
& =\frac{x-1}{\left(x^{k}-1\right)\left(x^{h}-1\right)}-\frac{1}{h k(x-1)}
\end{aligned}
$$

Next put $x=1+t$ in (3.4) and expand both members in ascending powers of $t$. We find without difficulty that the right member of (3.4) becomes

$$
-\frac{h+k-2}{2 h k}+\frac{h^{2}+3 h k+k^{2}-3 h-3 k+1}{12 h k} t+\cdots
$$

Comparison of coefficients of $t$ in both sides of (3.4) leads at once to

$$
\begin{array}{r}
-\frac{1}{k} \sum_{\zeta \neq 1} \frac{\zeta}{\zeta-1} \frac{1}{\zeta^{h}-1}-\frac{1}{h} \sum_{\eta \neq 1} \frac{\eta}{\eta-1} \frac{1}{\eta^{k}-1} \\
=\frac{h^{2}+3 h k+k^{2}-3 h-3 k+1}{12 h k} .
\end{array}
$$

Therefore by (2.2) and the corresponding formula for $s(k, h)$, we have

$$
\bar{s}(h, k)+\bar{s}(k, h)=\frac{h^{2}+3 h k+k^{2}+1}{12 h k},
$$

which is the same as (1.2).

4. The generalized reciprocity formula. The identity (3.4) implies a good deal more than (1.2). For example, for $x=0$, we get

$$
\frac{1}{k} \sum_{\zeta \neq 1} \frac{\zeta-1}{\zeta^{h}-1}+\frac{1}{h} \sum_{\eta \neq 1} \frac{\eta-1}{\eta^{k}-1}=1-\frac{1}{h k},
$$

while if we use the constant term in (3.5), we find that

$$
\frac{1}{k} \sum_{\zeta \neq 1} \frac{\zeta}{\zeta^{h}-1}+\frac{1}{h} \sum_{\eta \neq 1} \frac{\eta}{\eta^{k}-1}=\frac{h+k-2}{2 h k} .
$$

Again if we multiply by $x$ and let $x \rightarrow \infty$, we get 


$$
\frac{1}{k} \sum_{\zeta \neq 1} \zeta \frac{\zeta-1}{\zeta^{h}-1}+\frac{1}{h} \sum_{\eta \neq 1} \eta \frac{\eta-1}{\eta^{k}-1}=-\frac{1}{h k}
$$

More generally, expanding (3.4) in descending powers of $x$, we have

$$
\frac{1}{k} \sum_{\zeta \neq 1} \zeta^{r} \frac{\zeta-1}{\zeta^{h}-1}+\frac{1}{h} \sum_{\eta \neq 1} \eta^{r} \frac{\eta-1}{\eta^{k}-1}=\left\{\begin{array}{l}
-\frac{1}{h k}(1 \leq r<h+k-1) \\
1-\frac{1}{h k} \quad(r=h+k-1) .
\end{array}\right.
$$

By continuing the expansion of (3.5) we can also show that

$$
h \sum_{\zeta \neq 1} \frac{\zeta}{(\zeta-1)^{r}\left(\zeta^{h}-1\right)}+k \sum_{\eta \neq 1} \frac{\eta}{(\eta-1)^{r}\left(\eta^{k}-1\right)}
$$

is a polynomial in $h, k$, but the explicit expression seems complicated. A more interesting result can be obtained as follows. First we divide both sides of (3.4) by $x-1$ so that the left member becomes

$$
\begin{gathered}
\frac{1}{k} \sum_{\zeta} \frac{\zeta}{\zeta^{h}-1}\left(\frac{1}{x-\zeta}-\frac{1}{x-1}\right)+\frac{1}{h} \sum_{\eta} \frac{\eta}{\eta^{k}-1}\left(\frac{1}{x-\eta}-\frac{1}{x-1}\right) \\
\quad=\frac{1}{k} \sum_{\zeta} \frac{\zeta}{\zeta^{h}-1} \frac{1}{x-\zeta}+\frac{1}{h} \sum_{\eta} \frac{\eta}{\eta^{k}-1} \frac{1}{x-\eta}-\frac{h+k-2}{2 h k(x-1)}
\end{gathered}
$$

by (4.2). We now put $x=e^{t}$. Transposing the last term above to the right we find that the right member has the expansion

(4.5) $\frac{1}{h k} \sum_{m=0}^{\infty} \frac{(B h+B k)^{m} t^{m-2}}{m !}+\frac{h+k}{2 h k} \sum_{m=0}^{\infty} \frac{B_{m} t^{m-1}}{m !}+\frac{1}{h k} \sum_{m=0}^{\infty} \frac{(m-1) B_{m} t^{m-2}}{m !}$,

where the $B_{m}$ are the Bernoulli numbers. In the left member we put

$$
\frac{1-\zeta}{e^{t}-\zeta}=\sum_{m=0}^{\infty} H_{m}(\zeta) \frac{t^{m}}{m !}
$$

where the $H_{m}(\zeta)$ are the so-called "Eulerian numbers"; we thus get 
(4.6) $\frac{1}{k} \sum_{m=0}^{\infty} \frac{t^{m}}{m !} \sum_{\zeta} \frac{H_{m}\left(\zeta^{-1}\right)}{(\zeta-1)\left(\zeta^{-h}-1\right)}+\frac{1}{h} \sum_{m=0}^{\infty} \frac{t^{m}}{m !} \sum_{\eta} \frac{H_{m}\left(\eta^{-1}\right)}{(\eta-1)\left(\eta^{-k}-1\right)}$.

But by [3, formula $(6.6)]$, for $p$ odd $>1$,

$$
\frac{p}{k^{p}} \sum_{\zeta} \frac{H_{p-1}(\zeta)}{(\zeta-1)\left(\zeta^{-h}-1\right)}=s_{p}(h, k)
$$

where [1]

$$
s_{p}(h, k)=\sum_{r(\bmod k)} \bar{B}_{1}\left(\frac{r}{k}\right) \bar{B}_{p}\left(\frac{h r}{k}\right)
$$

and $\bar{B}_{r}(x)$ is the Bernoulli function. Thus the coefficient of $t^{p-1} /(p-1)$ ! in $(4.6)$ is

$$
\frac{1}{p}\left\{k^{p-1} s_{p}(h, k)+h^{p-1} s_{p}(k, h)\right\},
$$

while the corresponding coefficient in $(4.5)$ is

$$
\frac{1}{p(p+1) h k}(B h+B k)^{p+1}+\frac{1}{(p+1) h k} B_{p+1} .
$$

Hence equating (4.7) and (4.8) we get Apostol's formula [1, Theorem 1]:

$$
(p+1)\left\{h k^{p} s_{p}(h, k)+k h^{p} s_{p}(k, h)\right\}=(B h+B k)^{p+1}+p B_{p+1}
$$

for $p$ odd $>1$. Note that $s_{1}(h, k)=\bar{s}(h, k)$.

\section{REFERENCES}

1. T. M. Apostol, Generalized Dedekind sums and transformation formulae for certain Lambert series, Duke Math. J. 17 (1950), 147-157.

2. - Theorems on generalized Dedekind sums, Pacific J. Math. 2 (1950), 1-9.

3. L. Carlitz, Some theorems on generalized Dedekind sums, Pacific J. Math. 3(1953), $513-522$.

4. H. Rademacher and A. Whiteman, Theorems on Dedekind sums, Amer. J. Math. 63 (1941), $377-407$.

5. L. Redei, Elementarer Beweis und Verallgemeinerung einer Reziprozitätsformel von Dedekind, Acta Sci. Math. Szeged 12, Part B (1950), 236-239. 



\section{PACIFIC JOURNAL OF MATHEMATICS}

\section{EDITORS}

\author{
R. M. BOEINSON \\ University of California \\ Berkeley 4, California \\ E. HewitT \\ University of Washington \\ Seattle 5 , Washington
}

\section{R. P. DILWOR TH}

California Institute of Technology

Pasadena 4, California

E. F. BECKENBACH

University of California

Los Angeles 24, California

\section{ASSOCIATE EDITORS}

$\begin{array}{ll}\text { H. BUSEMANN } & \text { P. R. HALMOS } \\ \text { HERBERT FFDERER } & \text { IIEINZ HOPF } \\ \text { MARSHALL IJALL } & \text { R. D. JAMES }\end{array}$

\author{
BøRGE JESSEN \\ PAUL LÉVY \\ GEORGE PÓLYA
}

\author{
J. J. STOKER \\ E. G. STR AUS \\ KÔSAKU YOSIDA
}

\section{SFONSORS}

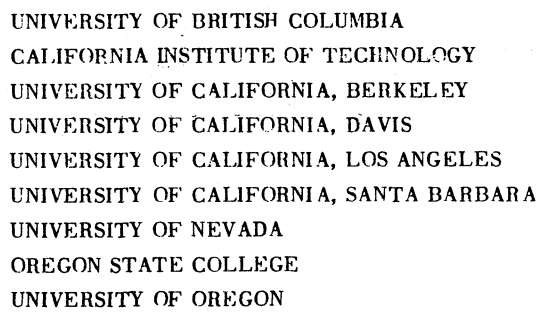

\author{
UNIVERSITY OF SOUTHERN CALIFORNIA \\ STANFORD RESEARCH INSTITUTE \\ STANFORD UNIVERSITY \\ WASHINGTON STATE COLLEGE \\ UNIVERSITY OF WASHINGTON \\ AMERICAN MATHEMATICAL SOCIETY \\ NATIONAL BUREAU OF STANDARDS, \\ INSTITUTE FOR NUMERICAL ANALYSIS
}

Mathematical papers intended for publication in the Pacific Journal of Mathematics should be typewritten (double spaced), and the author should keep a complete copy. Manuscripts may be sent to any of the editors except Robinson, whose term expires with the completion of the present volume; they might also be sent to M.M. Schiffer, Stanford University, Stanford, California, who is succeeding Robinson. All other communications to the editors should be addressed to the managing editor, E. F. Beckenbach, at the address given above.

Authors are entitled to receive 100 free reprints of their published papers and may obtain additional copies at cost.

The Pacific Journal of Mathematics is published quarterly, in March, June, September, and December. The price per volume (4 numbers) is $\$ 8.00$; single issues, $\$ 2.50$. Special price to individual faculty members of supporting institutions and to individual members of the American Mathematical Society: $\$ 4.00$ per volume; single issues, $\$ 1.25$.

Subscriptions, orders for back numbers, and changes of address should be sent to the publishers, University of California Press, Berkeley 4, California.

Printed at Ann Arbor, Michigan. Entered as second class matter at the Post Office, Berkeley, California.

\section{UNIVERSITY OF CALIFORNIA PRESS • BERKELEY AND LOS ANGELES}




\section{Pacific Journal of Mathematics}

\section{Vol. 3, No. 3 \\ May, 1953}

L. Carlitz, Some theorems on generalized Dedekind sums ............ 513

L. Carlitz, The reciprocity theorem for Dedekind sums ............. 523

Edward Richard Fadell, Identifications in singular homology theory..... . . 529

Harley M. Flanders, A method of general linear frames in Riemannian

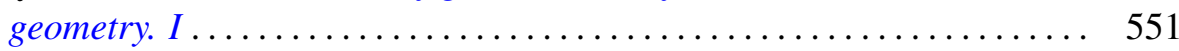

Watson Bryan Fulks, The Neumann problem for the heat equation ........ 567

Paul R. Garabedian, Orthogonal harmonic polynomials.............. 585

R. E. Greenwood and Andrew Mattei Gleason, Distribution of round-off errors for running averages .............................. 605

Arthur Eugene Livingston, The space $H^{p}, 0<p<1$, is not normable ... 613

M. N. Mikhail, On the order of the reciprocal set of a basic set of polynomials .......................................... 617

Louis Joel Mordell, On the linear independence of algebraic numbers . . . . 625

Leo Sario, Alternating method on arbitrary Riemann surfaces .......... 631

Harold Nathaniel Shapiro, Iterates of arithmetic functions and a property of the sequence of primes.............................. 647

H. Shniad, Convexity properties of integral means of analytic functions . . . . 657

Marlow C. Sholander, Plane geometries from convex plates ........... 667 